\title{
Samsun ili ve ilçelerinde yetiştirilen Anadolu mandalarının dışkı örneklerinde Escherichia coli 0157:H7'nin tespiti
}

\author{
Çağatay Nuhay ${ }^{1}$, Timur Gülhan² \\ ${ }^{1}$ Vezirköprü İlçe Gıda Tarım ve Hayvancılık Müdürlüğ̈̈, Vezirköprü, Samsun \\ ${ }^{2}$ Ondokuz Mayls Üniversitesi, Veteriner Fakültesi, Mikrobiyoloji AD, Samsun
}

Geliş Tarihi / Received: 25.05.2017, Kabul Tarihi / Accepted: 01.06.2017

\begin{abstract}
Özet: Mandalar, pek çok hayvan türü gibi bazı hastalıkların duyarlı hayvan popülasyonlarına ve insanlara bulaştırılmasında rol oynamaktadır. Enterohemorajik Escherichia coli (EHEC) suşları, insanlarda hemorajik kolitis (HC) ve hemorajik üremik sendrom (HUS) başta olmak üzere ölümcül enfeksiyonlara neden olmaktadır. Bu enfeksiyonlardan sorumlu başlıca EHEC serotipinin E. coli O157:H7 olduğu ortaya konulmuştur. Bu araştırmada, Samsun ili ve ilçelerindeki Anadolu Mandalarına ait 1000 dışkı örneği E. coli O157:H7 açısından standart kültürel metot ile incelendi. İncelenen 1000 dışk1 örneğinden 38 (\%3.8) E. coli O157:H7 serotipi, 400 (\%40) E. coli O157:H7 serotipi yönünden negatif E. coli olmak üzere toplam $438(\% 43.8)$ E. coli izole ve identifiye edildi. İzolatların tamamı penisilin $\mathrm{G}$ ve eritromisine dirençli, danofloksasin, amokssisilin+klavulanik asit, sefaperazon, ampisilin+sulbaktam, oksitetrasiklin ve ampisiline duyarlı olarak bulundu. Bu araştırma ile bölgemizde ilk kez Anadolu Mandalarına ait dışkı örnekleri E. coli O157:H7 serotipi yönünden incelendi. Bu araştırmadan elde edilen verilerin, yöremizde yapılacak benzer çalışmalara kaynak teşkil edebileceği kanısına varıldı.
\end{abstract}

Anahtar kelimeler: Anadolu mandası, Antibiyotik dirençlilik, Dışk1, E. coli O157:H7

\section{Determination of Escherichia coli 0157:H7 in Anatolian buffaloes' feces in and around Samsun}

\begin{abstract}
Buffaloes are involved in the transmission of certain diseases, such as many animal species, to susceptible animal populations and humans. Enterohaemorrhagic Escherichia coli (EHEC) strains cause lethal infections in human mainly hemorrhagic colitis (HC) and haemorrhagic uremic syndrome (HUS). The major EHEC serotype responsible for these infections is E. coli O157: H7. In this study, 1000 fecal samples belonging to Anatolian Buffaloes in the provinces and districts of Samsun were examined for E. coli O157:H7 by standard cultural methods. Totally 438 (43.8\%) E. coli were isolated and identified from examined 1000 stool samples including 38 (3.8\%) for E. coli O157: H7 serotype and $400(40 \%)$ for none $E$. coli $\mathrm{O} 157$ : H7 . All of isolates were found to be resistance to penicillin $\mathrm{G}$ and erythromycin, while they were found to be susceptible to danofloxacin, amoxicillin+clavulanic acid, cefoperazone, ampicillin+sulbactam, oxytetracycline and ampicillin. Fecal samples obtained from Anatolian Buffaloes were examined first time in our region respect to E. coli $\mathrm{O} 157: \mathrm{H} 7$ serotype. We concluded that the data obtained from this research can constitute a resource to similar studies in our region.
\end{abstract}

Key words: Anatolian buffaloes, Antibiotic resistance, Feces, E. coli O157:H7

\section{Giriş}

Manda, et, süt ve çeki hayvanı olarak dünya çapında, özellikle belirli ülkelerde yaygın olarak, yetiştirilen Artiodactyla takımında, Bovidae ailesinde Bubalus sinıfinda bir hayvandir. Afrika yabani mandas1 (Syncerus caffer) ve Asya mandas1 (Bubalus bubalis) olarak gruplandırılmaktadır. Evcil ve yabani formlardan köken alan mandaların yaklaşık 74 ırkı bulunmaktadır. Bu ırklar kabaca, bataklık ve nehir mandaları olarak ikiye ayrılmaktadır. Bataklık mandaları yük hayvanı olarak kullanılırken, nehir mandaları et ve süt yönlü yetiştirilmektedir. Türkiye'deki mandalar, nehir mandalarının bir alt grubu olan Akdeniz mandalarından köken almakta ve Anadolu mandası olarak isimlendirilmektedir (Şekil 1). Türkiye'de manda yetiştiriciliği; Karadeniz Bölgesinde sahil şeridinde Samsun ve Sinop'ta, iç kesimlerde ise Tokat, Çorum ve Amasya'da; İç Anadolu Bölgesinde Sivas ve Yozgat'ta; Ege Bölgesinde Afyon'da; Marmara Bölgesinde İstanbul'da; Doğu Anadolu Bölgesinde Muş’ta; Güneydoğu Anadolu Bölgesinde Diyarbakır'da yoğunlaşmıştır. Dünya çapında son verilere göre yaklaşı 177 milyon manda bulunmaktadır. Ülkemizde 134.000 civarında manda yetiştirildiği, Samsun ilinde ise yaklaşık 19. 000 manda bulunduğu bildirilmektedir [2]. 


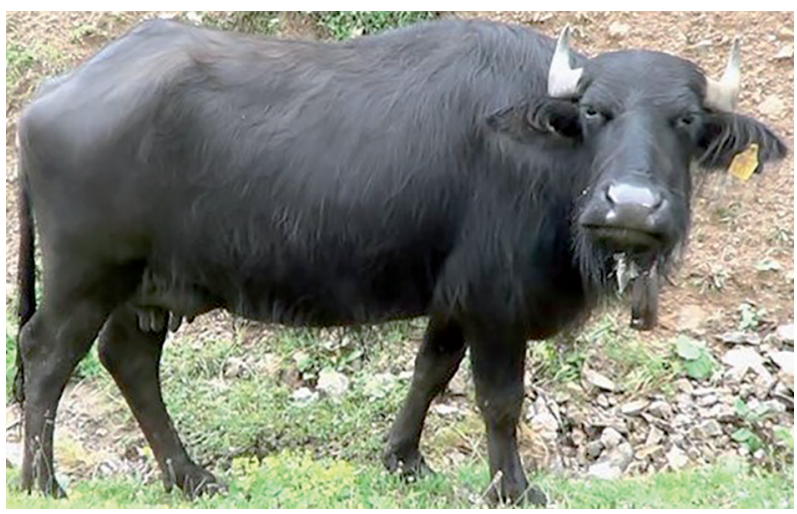

Şekil 1. Anadolu Mandası

EHEC grubu zoonotik orijinli patojenik gruptur ve birçok hayvan türünün barsak florasında bulunabilmektedir. Fakat ruminantların EHEC'nin ve özellikle E. coli O157:H7'nin birincil rezervuarı olduğu bilinmektedir. Bugüne kadar yaklaşık 500 EHEC serotipi sı̆̆ırlardan izole edilmiştir. E. coli O157:H7 infeksiyonları sığırlarda asemptomatik olduğu için genellikle etken bu hayvanlarda kommensal olduğu düşünülmektedir. Ancak, E. coli O157:H7 sı̆̆ırlar için kommensal değildir. Hasta hayvanların sindirim sistemi incelendiğinde küçük mukozal hemorajiler ve fokal peteşilerle karakterize barsak lezyonları görülmekte ve böyle hayvanlar aylarca etkeni dışkılarıyla çıkartabilmektedirler. İnsan için yüksek derecede virulanse sahip olan etken sadece kontamine gida veya suyun tüketilmesiyle değil, EHEC pozitif hayvanlar veya ortamlarla temas ile de bulaşabilmektedir [7].

E. coli $\mathrm{O} 157$ serotipinin diğer VTEC serotiplerinden ayırt edilmesinde kullanılan en önemli özellikler sorbitolü fermente edememesi (sorbitol negatif), $\beta$-glukorinidaz negatif olması ve $44-45^{\circ} \mathrm{C}$ 'de üreyememesidir. Bununla birlikte, sorbitol pozitif E. coli $\mathrm{O} 157$ suşları da izole edilmektedir. Bu serotipin belirlenmesinde sorbitol MacConkey agar (SMAC), cefixime-SMAC (CR-SMAC), SMAC'ya cefixime+potasyum tellurite kombinasyonu eklenmesi ile elde edilen CT-SMAC gibi besiyerlerinde, 5-bromo-5-chloro-3-indoxyl- $\beta$-D-glucuronide veya 4-methylumbelliferyl- $\beta$-D- glucuronide içeren ortamlarda direk kültür tekniği, bakteriyolojik kültürden sonra O157 spesifik antikorlarla kaplanmış boncukları kullanarak immunomanyetik seperasyon ve selektif besiyerlerinde üretildikten sonra lateks aglütinasyon testleri yaygın olarak kullanılmakta- dir [15]. E. coli $\mathrm{O} 157: \mathrm{H}-$ ve $\mathrm{O} 157: \mathrm{H} 7$ serotiplerinin özellikle dışkı örneklerinde saptanmasında, SMAC besi yerinin kullanılarak yapılan direkt kültür tekniğinin basit, ucuz ve güvenilir bir yöntem olduğu bildirilmiştir [21]. Bu besi yerinde sorbitol negatif bakteriler, ticari antiserumlar veya lateks aglütinasyon test kitleri ile test edilebilmektedir.

E. coli tedavi amaçlı kullanılan antibiyotiklere genellikle duyarlı olmakla birlikte, pek çok enteropatojenik bakteri türünde olduğu gibi, E. coli izolatları arasında da antibiyotik dirençliliği giderek artmaktadır [13].

Literatür taramalarında, manda dışkılarından $E$. coli O157:H7 serotipinin tespitine yönelik çalışma sayısının, diğer hayvan türleriyle kıyaslandığında, yetersiz olduğu görülmüştür. Ülkemizde etkenin manda dışkılarında tespitine yönelik iki çalışmaya rastlanılmıştır [24, 25]. Samsun ili ve çevresinde manda yetiştiriciliği yoğun olarak yapılmaktadır. $\mathrm{Bu}$ çalışma ile bölgemizde ilk kez Anadolu mandalarının dışk1 örnekleri E. coli O157:H7 serotipi yönünden incelendi. Manda dışkılarında etkenin varlığı ve sıklığ 1 ortaya konuldu. Ayrıca izolatların belirli antibiyotiklere dirençlilik/duyarlılık durumları araştırıldı.

\section{Materyal ve Metot}

Dışkı Örnekleri: Çalışmanın materyalini Samsun ilçelerinde yetiştiriciliği yapılan Anadolu Mandalarından sağlanan 1000 adet dışkı örneği oluşturdu (Şekil 2). Bu amaçla alınan dışkı sayıları ve merkezler Tablo 1'de sunuldu.

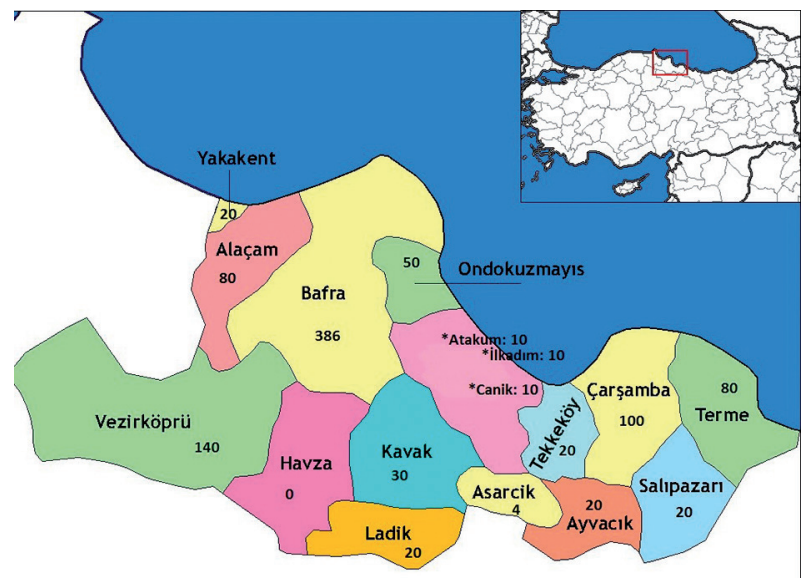

Şekil 2. Anadolu mandası dışkı örneklerinin toplandığ 1 merkezler 
Tablo 1. Anadolu mandası dışkı örneklerinin toplandığg merkezler ve dışkı sayıları

\begin{tabular}{lcc}
\hline Merkez & Manda sayısı & Alınan dışkı sayısı \\
\hline Ayvacık & 6 & 4 \\
İlkadım & 20 & 10 \\
Canik & 42 & 10 \\
Atakum & 62 & 10 \\
Yakakent & 79 & 20 \\
Tekkeköy & 148 & 20 \\
\hline Salıpazarı & 206 & 20 \\
\hline Asarcık & 335 & 20 \\
\hline Ladik & 408 & 20 \\
Kavak & 428 & 30 \\
Ondokuz Mayıs & 1116 & 50 \\
Terme & 1496 & 80 \\
Çarşamba & 1857 & 100 \\
Alaçam & 1936 & 80 \\
Vezirköprü & 2869 & 140 \\
Bafra & 6972 & 386 \\
Toplam & $\mathbf{1 7 . 9 8 0}$ & $\mathbf{1 0 0 0}$ \\
\hline
\end{tabular}

Besiyerleri ve Suplementler: D1şkı örneklerinden E. coli $\mathrm{O} 157: \mathrm{H} 7$ izolasyonu amaciyla modifiye tryptic soy broth (mTSB, Oxoid), sorbitol MacConkey agar (SMAC, Oxoid), tryptic soy agar (TSA, Oxoid,) ve tryptic soy buyyon (TSB, Oxoid) kullanıldı. Selektif besi yeri elde etmek için ise novobiocin (Oxoid), cefixime $(0.05 \mu \mathrm{g} / \mathrm{ml})$ ve potassium tellurite $(2.5 \mu \mathrm{g} / \mathrm{ml})$ (Oxoid) suplementlerinden yararlanild1.

Antiserumlar: E. coli suşlarında O157 serotipinin belirlenmesi için O157 lateks aglütinasyon test kiti (Oxoid DR620M, UK), H7 serotipinin tespitinde ise $\mathrm{H} 7$ monovalan antiserumu (Denka Seiken, Japonya) kullanıldı.

İzolasyon ve İdentifikasyon: Dışkı örneklerinden E. coli izolasyonu konvansiyonel yöntemlere göre yap1ld1. Escherichia coli O157:H7 izolasyonu amaciyla önceden populasyon yoğunluğu belirlenen mandalardan steril dışkı toplama kaplarına alınan dışkı örnekleri kısa sürede ve soğuk zincirde, OMÜ Veteriner Fakültesi Mikrobiyoloji Anabilim Dalı laboratuvarına getirilerek selektif zenginleştirme (direkt kültür) tekniği ile incelendi.
Bu amaçla, 1 g dışk1 örneği, $20 \mu \mathrm{g} / \mathrm{ml}$ novobiocin suplementi içeren $9 \mathrm{ml}$ modifiye triptic soy broth (mTSB) besiyerine aktarıld 1 ve homojenize edildi. Homojenizattan hazırlanan 10 katlı seri sulandirmalar cefixime $(0.05 \mu \mathrm{g} / \mathrm{ml})$ ve potassium tellurite $(2.5$ $\mu \mathrm{g} / \mathrm{m}$ ) içeren sorbitol MacConkey agar (CT-SMAC) besi yerine ekilerek direkt kültür (direkt pleyting) yapıld1. CT-SMAC agarda üreyen sorbitol fermentasyonu negatif, renksiz koloniler ayrilarak lateks aglütinasyon testi ile $E$. coli $\mathrm{O} 157$ ve monovalan $\mathrm{H} 7$ antiserumu ile $\mathrm{H} 7$ yönünden incelendi.

İzole ve identifiye edilen $E$. coli suşlarında $\mathrm{O} 157$ serotipinin belirlenmesinde ticari E. coli O157 lateks test kiti kullanıldı. Test üretici firmanın önerileri doğrultusunda yapıldı. Kısaca, E. coli suşlarının taze kültürleri CT-SMAC agara ekilerek 37 ${ }^{\circ} \mathrm{C}$ 'de aerobik koşullarda 24 saat inkübe edildi. $\mathrm{Bu}$ ortamda üreyen sorbitol fermentasyonu ve $\beta$-glukuronidaz negatif renksiz koloniler şüpheli olarak değerlendirildi. Saflaştırılarak ayrılan şüpheli koloniler lateks aglütinasyon testi ile incelendi. Test, pozitif kontrol lateksi ve negatif kontrol süspansiyonu ile doğrulandi.

E. coli $\mathrm{O} 157$ olarak saptanan susların $\mathrm{H}$ antijen tipinin belirlenmesi amaciyla ticari $\mathrm{H} 7$ monovalan antiserumu kullanıldı. Test prospektüsüne göre gerçekleştirildi. Kısaca, izolatların taze sıvı kültürlerinden craigie tüplü yar1-katı besiyerlerine ekimler yapılarak 3-5 kez flagella oluşumunu artırmak için pasajland1. Yarı katı besi yerinden BHI sıvı besi yerine ekilen kültürler $37^{\circ} \mathrm{C}$ ' de bir gece inkübe edildi. İnkübasyon süresi sonunda sıvı kültürler üzerine eşit miktarda \%1'lik formalin ilave edildi. Ayrı ayrı test tüplerine 3'er damla $\mathrm{H}$ antiserumu damlatılacak ve her tüpe $0.5 \mathrm{ml}$ bakteri kültüründen eklendi. Tüpler iyice karıştırıldıktan sonra $56{ }^{\circ} \mathrm{C}$ 'de 1 saat su banyosunda bekletildi ve aglütinasyonlar çıplak gözle değerlendirildi. Aglütinasyon gösteren izolatlar E. coli $\mathrm{O} 157: \mathrm{H} 7$ olarak tiplendirildi.

Antibiyotik Duyarlılık Testi: İzolatların ampisilin $(10 \mu \mathrm{g})$, eritromisin $(15 \mu \mathrm{g})$, penisillin $\mathrm{G}$ $(10 \mu \mathrm{g})$, sefaperazon $(75 \mu \mathrm{g})$, danofloksasin (5 $\mu \mathrm{g})$, amokssisilin+klavulanik asit $(25 \mu \mathrm{g})$, ampisilin+sulbaktam $(20 \mu \mathrm{g})$, oksitetrasiklin $(30 \mu \mathrm{g})$ antibiyotiklerine dirençlilik/duyarlılık durumlarının belirlenmesinde Clinical and Laboratory Standards Institute tarafindan önerilen standart disk diffüzyon tekniği kullanıldı [5]. 


\section{Bulgular}

İzolayon ve İdentifikasyon Bulguları: İncelenen 1000 dışk1 örneğinden 38 (\%3.8) E. coli O157:H7 serotipi, $400(\% 40)$ E. coli $\mathrm{O} 157: \mathrm{H} 7$ serotipi yönünden negatif $E$. coli olmak üzere toplam 438 (\%43.8) $E$. coli suşu izole ve identifiye edildi. İzole edilen $E$. coli ve E. coli $\mathrm{O} 157: \mathrm{H} 7$ suşlarının dişkı örneklerinin sağlandığı merkezlere göre dağılımı Tablo 2'de sunuldu.

Tablo 2. E. coli ve E. coli $\mathrm{O} 157: \mathrm{H} 7$ suşlarının izole edildiği merkezlere göre dağ 11 เımı

\begin{tabular}{lcccc}
\hline Merkez & $\begin{array}{c}\text { Dışkı } \\
\text { sayısı }\end{array}$ & $\begin{array}{c}\text { O157:H7 negatif } \\
\text { E. coli }(\%)\end{array}$ & $\begin{array}{c}\boldsymbol{E} \text {. coli } \\
\text { O157:H7 (\%) }\end{array}$ & $\begin{array}{c}\text { Toplam } \\
\text { coli }(\%)\end{array}$ \\
\hline Ayvacık & 4 & $2(50)$ & - & $2(50)$ \\
İlkadım & 10 & $5(50)$ & - & $5(50)$ \\
Canik & 10 & $5(50)$ & - & $5(50)$ \\
Atakum & 10 & $5(50)$ & - & $5(50)$ \\
\hline Tekkeköy & 20 & $10(50)$ & $2(10)$ & $12(60)$ \\
Yakakent & 20 & $15(75)$ & - & $15(75)$ \\
\hline Asarcık & 20 & $15(75)$ & $2(10)$ & $17(85)$ \\
Salıpazarı & 20 & $15(75)$ & - & $15(75)$ \\
\hline Ladik & 20 & $15(75)$ & - & $15(75)$ \\
Kavak & 30 & $15(50)$ & $2(6.7)$ & $17(56.7)$ \\
\hline Ondokuz Mayıs & 50 & $25(50)$ & $2(4)$ & $27(54)$ \\
\hline Alaçam & 80 & $25(31.3)$ & $2(2.5)$ & $27(33.8)$ \\
\hline Terme & 80 & $25(31.3)$ & $4(5)$ & $29(36.3)$ \\
Çarşamba & 100 & $50(50)$ & $4(4)$ & $54(54)$ \\
\hline Vezirköprü & 140 & $55(39.3)$ & $6(4.3)$ & $61(43.6)$ \\
\hline Bafra & 386 & $118(30.6)$ & $14(3.6)$ & $132(34.2)$ \\
Toplam & $\mathbf{1 0 0 0}$ & $\mathbf{4 0 0 ( 4 0 )}$ & $\mathbf{3 8 ( 3 . 8 )}$ & $\mathbf{4 3 8}(\mathbf{4 3 . 8})$ \\
\hline & & & &
\end{tabular}

Antibiyotik Duyarlılık Testi Sonuçları: İzole edilen $438 E$. coli susunun tamamı eritromisin ve penisilin G'ye dirençli, danofloksasin, amokssisilin+klavulanik asit, sefaferazon, ampisilin+sulbaktam, oksitetrasiklin ve ampisiline duyarlı bulundu.

\section{Tartışma ve Sonuç}

Mandaların diğer hayvanlarda olduğu gibi pek çok patojen etkeni taşıdıkları, bazı hastalıkların duyarlı hayvan popülasyonlarına ve insanlara bulaştırılmasında rol oynadıkları tespit edilmiştir. Yabani ve evcil mandalarda yapılan çalışmalarda zoonoz karaktere de sahip pek çok bakteriyel etkenin varlığ 1 ve yaygınlığı ortaya konulmuştur $[10,22,25]$.
Çeșitli hayvan türlerinde $[5,9,12]$ olduğu gibi mandalarda da E. coli $\mathrm{O} 157: \mathrm{H} 7$ ile ilgili farklı ülkelerde gerçekleştirilen çalışmalar bulunmaktadır.

İtalya'da yapılan bir araştırmada 289 manda dışk1 örneğinden 42'sinde (\%14.5) VTEC 157 suşu belirlenmiştir [8]. Benzer bir çalışmada [12], 174 manda dışkısından 25 (\%14.4) STEC O157 izole edilmiştir. Naag ve ark. [17] ishalli manda yavrularına ait 32 dışkı örneğinin 19'undan (\%59.4) VTEC izolasyonu yapmışlardır. Hindistan'da gerçekleștirilen bir çalışmada [16] mandalarda \%13.4 (8/60) oranında VTEC tespit edilmiştir.

Mahanti ve ark. [14] manda dışkılarından izole ettikleri 363 E. coli suşundan 24'inin (\%6.6) O157 haricinde diğer STEC serotipi olduğunu rapor etmişlerdir. Çalışmada izolatların \%95.8'i eritromisine, $\% 62.5$ 'i sefalotine, $\% 54.2$ 'si amikasine, $\% 4.2$ 'si de amoksisiline dirençli bulunmuştur. Aynı araştırıcıların yaptıkları başka bir çalışmada [15] manda dışkılarından izole edilen 363 E. coli suşunun 26's (\%6.8) O157 olmayan ETEC olarak belirlemiştir. Benzer bir çalışmada 237 manda rektal svap örneğinden 64 (\%27) STEC izole edilmiştir. İzolatların tamamı O157 serotipi açısından negatif bulunmuştur [27].

İshalli manda yavrularından izole edilen hemolitik E. coli suşlarının antibiyotik duyarlılıklarını belirlemek amacıyla yapılan bir araștırmada [18], 169 dışkı örneğinden 94 (\%55.6) izolat saptanmıştır. İzole edilen 94 hemolitik E. coli suşunun, tamamı penisiline, 44'ü (46.8) ampisilin ve amoksisilin+klavulonik aside, 32'si (\%34) tetrasikline 18 'i (\%19.1) enrofloksasine dirençli bulunmuştur. İzolatların 40’1 (\%42.5) O157 serotipi olarak tiplendirilmiştir. O157 izolatlarından 40'ının (\%100) penisiline, 26'sinın (\%65) ampisiline, 25'inin (\%62.5) amoksisilin+klavulonik aside, 12'sinin (\%30) entrofloksasine ve 9'unun (\%22.5) tetrasikline dirençli olduğu saptanmıştır. Benzer bir çalışmada [20] 50 manda rektal svap örneğinin 23'ünden (\%46) $E$. coli izole edilmiştir. Çalışmada, izolatların \%12.2'si enrofloksasine, \%22.5'i amoksisiline, \%33.3'ü eritromisine dirençli, tamamı siprofloksasin, gentamisin ve sefaleksine duyarlı bulunmuştur.

İran'da yapılan bir araştırmada [28] 360 manda dışkı örneğinden $340(\% 94.4)$ E. coli izole edilmiş ve 26's1 STEC olarak bulunmuştur. Bunların sadece 
1'i (\%3.8) O157 serotipi geri kalanı O157 olmayan STEC serotipi olarak tanımlanmıştır. 26 STEC izolatının tamamının ampisilin, eritromisin, neomisin ve streptomisine, 25'inin (\%96.1) amoksisiline, 18 'inin (\%69.2) kanamisine ve 4'ünün (\%15.3) de tetrasikline dirençli olduğu bildirilmiştir. Benzer bir çalışmada [4], 314 manda yavrusuna ait dışk1 örneğinden $220(\% 70.1)$ E. coli izole edilmiştir. İzolatların \%81.8'i ampisiline, \%74'ü oksitetrasikline, \%42.6's1 amoksisilin+klavulonik aside ve \%30.6's1 enrofloksasine dirençli bulunmuştur. 220 izolatın 4'ü (\%1.8) ETEC ve 6'sı (\%2.7) EHEC olarak bulunmuştur. Ancak patojen suşların hiçbirinde O157 serotipi saptanamamıştır.

Hindistan'da mandalarda enteropatojenik $E$. coli (EPEC) epidemiyolojisi üzerine gerçekleştirilen bir çalışmada [23], 43 manda dışkısının 35'inden (\%81.4) O157 olmayan E. coli serotipleri izole edilmiş, bunların sadece 1'i (\%2.3) EPEC olarak tanımlanmıştır. İzolatların tamamı ampisilin, amoksisilin, tetrasiklin ve enrofloksasine duyarlı bulunmuştur.

İran'da yapılan bir çalışmada [21], sağlıklı görünen mandalardan alınan 43 dışkı örneğinin 5'i O157:H7, 3'ü O157:H7/NM olmak üzere 8 (\%18.6) E. coli $\mathrm{O} 157$ serotipi tespit edilmiştir. Çalışmada, mandaların enterohemorajik E. coli O157 serotipinin insanlara bulaştırılmasında potansiyel önemine dikkat çekilmiştir.

Tanzanya'da yaban hayatında antibiyotiklere dirençli bakterileri belirlemek için yapılan bir araştırmada [13], 35 manda dışkısından izole edilen 31 E. coli (\%88.6) suşun 20'si (\%64.5) tetrasikline, 12 'si (\%38.7) ampisiline, 9'u (\%29) sefotaksim ve amoksisilin+klavulonik aside, 8'i (\%25.8) de enrofloksasine dirençli bulunmuştur. Benzer bir çalışmada [1], 25 manda dışkısından 20 E. coli $(\% 80)$ izole edilmiş, izolatların antibiyotik dirençlilik oranları eritromisin, ampisilin, terasikilin ve enrofloksasin sırasıyla $\% 100,90,80$ ve 75 olarak bildirilmiştir. Idrees ve ark. [11], manda orijinli 58 E. coli suşunda trimetoprime $\% 28$, ampisiline $\% 24$, sefotaksime $\% 16$ oranında dirençlilik saptamışlardır.

Farklı ülkelerde yapılan çalışmalarda mandalarda diğer EHEC serotiplerinin de yüksek oranlarda tespit edilmesi [3, 12], bu hayvanların zoonoz karakterdeki serotiplerin taşınmasındaki önemli potansiyele sahip olduğunu göstermektedir. Diğer yandan E. coli O157:H7 serotipi, başlıca zoonotik EHEC olmas1 nedeniyle öneme sahiptir. Bu bakteriyi taşıyan ve başlıca dışkı olmak üzere çeşitli yollarla saçabilen hayvanların tespiti, insanlardaki gıda kökenli salgınların önlenmesi açısından son derece önemlidir. Çeşitli ülkelerde mandaların dışkılarında etkenin varlığ 1 ortaya konulmasına rağmen [19, 21, 28], ülkemizde konuyla ilgili çok az araştırmaya rastlanılmıştır. Marmara bölgesinde yapılan bir araştırmada 28 manda karkas ve rektal svaplarında E. coli O157:H7'ye rastlanılamamıştır [29]. Türkiye'de Anadolu Mandalarına ait dışkı örneklerinden E. coli O157:H7'nin ilk izolasyonu Şeker ve Yardımcı [24] tarafından yapılmıştır. Çalışmada 300 dışkı örneğinden $11(\% 3.7)$ ve 213 çiğ sütten 3 (\%1.4) E. coli $\mathrm{O} 157: \mathrm{H} 7$ izole edilmiştir.

$\mathrm{Bu}$ çalışmada, incelenen 1000 manda dışkı örneğinden 38 (\%3.8) E. coli $\mathrm{O} 157: \mathrm{H} 7$ suşu izole ve identifiye edildi. Ayrıca dışkı örneklerinden O157:H7 serotipi açısından negatif 400 E. coli izolasyonu gerçekleştirildi. Araştırma kapsamında örnek toplanan manda populasyonlarında belirlenen toplam pozitiflik oranının farklı ülkelerde bildirilen oranlardan genelde düşük olduğu görüldü. Diğer yandan sonuçlar, ülkemizde izolasyon yapılan tek çalışma ile uyumlu bulundu. İzolasyon oranlarının diğer ülkelerdekilerden düşük olması, proje kapsamında alınan dışkı örneklerinin klinik olarak sağlıklı mandalardan sağlanmış olmasından kaynaklanabilir. Ayrıca çalışmalarda kullanılan metotların, örnek toplanan merkezlerin farklı coğrafik alanlara ait olması da sonuçları etkileyebilmektedir.

Sonuç olarak, bu çalışmada Samsun İli ve ilçelerinde halk elinde yetiştiriciliği yapılan Anadolu Mandalarının dışkı örneklerinde E. coli O157:H7'nin varlığ1, yaygınlığ1 ve hedef hayvan populasyonlarındaki taşıyıcılık oranları ilk kez incelendi. Çalışma kapsamındaki bazı Anadolu Mandası populasyonlarından sağlanan dışkılardan etken izole edilemezken, bazı populasyonlarda yüksek oranda tespit edildi. Toplam hayvan populasyonlarından izole edilen etkenin prevalansı ise \%3.8 olarak saptand1. Bu oran ülkemizde Ege bölgesinde bildirilen oranla paralellik göstermektedir. Zoonotik öneme sahip etkenin mandalardaki taşıyıcılık oranın yüksek olması önem arz etmektedir. İzole edilen suşlarda çoğul antibiyotik dirençliliğine rastlanılmaması 
önemli olarak değerlendirildi. Diğer yandan izolatların tamamının eritromisin ve penisiline direnç göstermesi, söz konusu antibiyotiklerin sahada yaygin olarak kullanılıyor olmasından kaynaklanabileceği kanısına varıldı.

Ülkemizde diğer hayvan türlerinde zoonotik öneme sahip etkenin belirlenmesine yönelik çok sayıda çalışma bulunmakla birlikte, mandalara ait verilerin çok yetersiz olduğu görülmektedir. Ülkemizin farklı bölgelerinde, manda yetiştiriciliğinin yapıldığı alanlarda konuyla ilgili kapsamlı çalışmalara ihtiyaç duyulmaktadır.

\section{Teşekkür}

Bu çalışma PYO.VET.1904.14.007 numaralı yüksek lisans tez projesi kapsamında gerçekleştirilmiştir.

Aynı isimli yüksek lisans tezinden özetlenmiştir.

\section{Kaynaklar}

1. Ahmadi M, Tokmechi A, Kazemnia A, (2008). Study of antimicrobial susceptibility and plasmid analysis of Escherichia coli in Iran, Urmia. J Vet Res. 63(2), 25-29.

2. Anonim, (2017). Gıda, Tarım ve Hayvancılık Bakanlığı, Hayvancılık Genel Müdürlüğü, Mart 2017 Verileri, Erişim adresi: http://www.tarim.gov.tr/sgb/Belgeler/ SagMenuVeriler/HAYGEM.pdf, Erişim Tarihi: 26.04.2017.

3. Beraldo LG, Borges CA, Maluta RP, Cardozo MV, Rigobelo EC, Avila FA, (2014). Detection of Shiga toxigenic (STEC) and enteropathogenic (EPEC) Escherichia coli in dairy buffalo. Vet Microbiol. 170, 162-166.

4. Borriello G, Lucibelli MG, De Carlo E, Auriemma C, Cozza D, Ascione G, Scognamiglio F, Iovane G, Galiero G, (2012). Characterization of enterotoxigenic E. coli (ETEC), Shigatoxin producing E. coli (STEC) and necrotoxigenic E. coli (NTEC) isolated from diarrhoeic Mediterranean water buffalo calves (Bubalus bubalis). Res. Vet Sci. 93, 18-22.

5. Clinical and Laboratory Standards Institute (CLSI) (2013). Performance standards for antimicrobial susceptibility testing; twenty-third informational supplement M100-S23. Wayne, PA.

6. Çabalar M, Boynukara B, Gülhan T, Ekin İH, (2001). Prevalence of rotavirus, Escherichia coli K99 and O157:H7 in healthy dairy cattle herds in Van, Turkey. Turk J Vet Anim Sci. 25, 191-196.

7. Ferens WA, Hovde CJ, (2011). Escherichia coli O157:H7: animal reservoir and sources of human infection. Foodborne Pathog Dis. 8(4), 465-487.

8. Galiero G, Conedera G, Alfano D, Caprioli A. (2005). Isolation of verocytotoxin-producing Escherichia coli O157 from water buffaloes (Bubalus bubalis) in southern Italy. Vet Rec. 156, 382-383.
9. Gülhan T, (2003). Sağlıklı görünen hayvanların dışkılarından izole edilen Escherichia coli suşlarının biyokimyasal, enterotoksijenik ve verotoksijenik özelliklerinin belirlenmesi. YYÜ Vet Fak Derg. 14(1), 102-109.

10. Hadimli HH, Pinarkara Y, Sakmanoğlu A, Sayin Z, Erganiş O, Uslu A, Al-Shattrawi HJ, (2017). Serotypes of Salmonella isolated from feces of cattle, buffalo, and camel and sensitivities to antibiotics in Turkey. Turk J Vet Anim Sci. 41, 193-198.

11. Idrees M, Shah MA, Michael S, Qamar R, Bokhari H, (2011). Antimicrobial resistant Escherichia coli strains isolated from food animals in Pakistan. Pakistan J Zool. 43(2), 303-310.

12. Islam MA, Mondol AS, de Boer E, Beumer RR, Zwietering MH, Talukder KA, Heuvelink AE, (2008). Prevalence and genetic characterization of Shiga toxin-producing Escherichia coli isolates from slaughtered animals in Bangladesh. Appl Environ Microbiol. 74, 5414-5421.

13. Katakweba AAS, Møller KS, Muumba J, Muhairwa AP, Damborg P. Rosenkrantz JT, Minga UM, Mtambo MMA, Olsen JE, (2014). Antimicrobial resistance in faecal samples from buffalo, wildebeest and zebra grazing together with and without cattle in Tanzania. J Appl Microbiol. 118, 966-975.

14. Mahanti A, Samanta I, Bandopaddhay S, Joardar SN, Dutta TK, Batabyal S, Sar TK, Isore DP, (2013). Isolation, molecular characterization and antibiotic resistance of Shiga toxin-producing Escherichia coli (STEC) from buffalo in India. Lett Appl Microbiol. 56, 291-298.

15. Mahanti A, Samanta I, Bandopaddhay S, Joardar SN, Dutta TK, Sar TK, (2014). Isolation, molecular characterization and antibiotic resistance of Enterotoxigenic E. coli (ETEC) and Necrotoxigenic $E$. coli (NTEC) from healthy water buffalo. Vet Arhiv. 84(3), 241-250.

16. Mishra RP, Jain U, Bist B, Verma AK, Kumar A, (2016). Prevalence of vero toxic Escherichia coli in fecal samples of domestic as well as wild ruminants in Mathura districts and Kanpur zoo. Vet World. 9(1), 71-74.

17. Naag D, Swamy M, Shrivastav AB, (2015). Detection of verotoxin producing strain of $E$. coli in buffalo calves. Buffalo Bulletin. 34(2), 227-229.

18. Nizza S, Mallardo K, Marullo A, Iovane V, De Martino L, Pagnini U, (2010). Antibiotic susceptibility of haemolytic E. coli strains isolated from diarrhoeic faeces of buffalo calves. Ital J Anim Sci. 9:e26, 134-136.

19. Oliveira MG, Brito JRF, Carvalho RR, Guth BEC, Gomes TAT, Vieira MAM, Kato MAMF, Ramos II. Vaz TMI, Irino K, (2007). Water buffaloes (Bubalus bubalis) identified as an important reservoir of Shiga toxin-producing Escherichia coli in Brazil. Appl Environ Microbiol. 73, 5945-5948.

20. Paul SK, Khan MSR, Rashid MA, Hassan J, Mahmud SMS, (2010). Isolation and characterization of Escherichia coli from buffalo calves in some selected areas of Bangladesh. Bangl J Vet Med. 8(1), 23-26.

21. Rahimi E, (2012). Prevalence and virulence genes of Escherichia coli $\mathrm{O} 157: \mathrm{H} 7 / \mathrm{NM}$ isolated from the feces of water buffaloes, camels, cattle, sheep and goats in Iran. Philipp J Vet Med. 49(2), 96-102. 
22. Rahimi E, Momtaz H, Behzadnia A, Baghbadorani ZT, (2014). Incidence of Listeria species in bovine, ovine, caprine, camel and water buffalo milk using cultural method and the PCR assay. Asian Pac J Trop Dis. 4(1), 50-53.

23. Rehman MU, Rashid M, Sheikh JA, Bhat MA, (2014). Molecular epidemiology and antibiotic resistance pattern of Enteropathogenic Escherichia coli isolated from bovines and their handlers in Jammu, India. J Adv Vet Anim Res. 1(4), 177-181.

24. Şeker E, Yardımcı H, (2008). First isolation of Escherichia coli $\mathrm{O} 157: \mathrm{H} 7$ from faecal and milk specimens from Anatolian water buffaloes (Bubalus bubalus) in Turkey. J S Afr Vet Assoc. 79, 167-170.

25. Şeker E, Yardımcı H, (2010). The aerobic bacterial flora of the nasal cavity in healthy Anatolian water buffalo calves. Ankara Üniv Vet Fak Derg. 57, 65-67.
26. Şeker E, Kuyucuoğlu Y, Sareyyüpoğlu B, Yardımcı H, (2010). PCR detection of Shiga toxins, enterohaemolysin and intimin virulence genes of Escherichia coli O157:H7 strains isolated from faeces of Anatolian water buffaloes in Turkey. Zoonoses Public Health. 57, 33-37.

27. Vu-Khac H, Cornick NA, (2008). Prevalence and genetic profiles of Shiga toxin-producing Escherichia coli strains isolated from buffaloes, cattle, and goats in central Vietnam. Vet Microbiol. 126, 356-363.

28. Yaghobzadeh N, Ownagh A, Mardani K, Khalili M, (2011). Prevalence, molecular characterization and serology of Shiga toxin producing Escherichia coli isolated from buffaloes in West Azerbaijan, Iran. Int J Vet Res. 5(2), 113-117.

29. Yılmaz A, Gün H, (2007). Manda karkasları ve rektal swaplarında Escherichia coli O157:H7 varlığının araştırılması. İstanbul Üniv Vet Fak Derg. 33(3), 59-65. 